\title{
Efficacy of a Closed-Set Auditory Training Protocol on Speech Recognition of Adult Hearing Aid Users
}

\author{
Ji Young Jeong ${ }^{1,2}$, Junghwa Bahng ${ }^{2,3}$, and Jae Hee Lee ${ }^{2,3}(\mathbb{D}$ \\ ${ }^{1}$ J. W. Hearing Aid Center, Andong; and ${ }^{2}$ Department of Audiology and Speech-Language Pathology, Hallym University of Graduate \\ Studies, Seoul; and ${ }^{3}$ HUGS Center for Hearing and Speech Research, Seoul, Korea
}

\section{객관식형 청능훈련 프로토콜이 보청기 착용 성인의 어음인지에 미치는 효과}

\author{
정지영 ${ }^{1,2}$ - 방정화 ${ }^{2,3}$ • 이재희 ${ }^{2,3}$ \\ 장원보청기센터, ${ }^{1}$ 한림국제대학원대학교 청각언어치료학과, ${ }^{2}$ 청각언어연구소 ${ }^{3}$
}

\author{
Received September 23, 2019 \\ Revised December 3, 2019 \\ Accepted December 20, 2019 \\ Address for correspondence \\ Jae Hee Lee, PhD \\ Department of Audiology and \\ Speech-Language Pathology, \\ HUGS Center for Hearing and \\ Speech Research, Hallym University \\ of Graduate Studies, \\ 427 Yeoksam-ro, Gangnam-gu, \\ Seoul 06198, Korea \\ Tel +82-2-2051-2942 \\ Fax $+82-2-3453-6618$ \\ E-mail leejaehee@hallym.ac.kr \\ Junghwa Bahng, PhD \\ Department of Audiology and \\ Speech-Language Pathology, \\ HUGS Center for Hearing and \\ Speech Research, Hallym University \\ of Graduate Studies, \\ 427 Yeoksam-ro, Gangnam-gu, \\ Seoul 06198, Korea \\ Tel +82-70-8680-6933 \\ Fax +82-2-3453-6618 \\ E-mail bahng.jh@gmail.com
}

Background and Objectives Auditory training involves active listening to auditory stimuli, and it has garnered attention in recent years because it enhances speech-in-noise recognition and the satisfaction of hearing aids. The purpose of this study was to determine the efficacy of a closed-set auditory training protocol for adult hearing aid users. We also evaluated the retention effect of training at a 1-month follow-up test after the completion of training.

Subjects and Method Twenty-two hearing-impaired listeners who have used bilateral hearing aids for more than two months participated in this study. Out of 22 participants, 12 participants (training group, TG) received an 8-week auditory training while 10 participants did not receive any training (non-training group, NTG). For training, three types of closed-set training materials (environmental sounds, words, and sentences) were used. The training was conducted eight times over eight weeks (one session per week, about one hour per session). The difficulty level was adjusted by controlling the number of closed-set choices and the signal-to-noise ratios. To determine the efficacy of training, open-set speech recognition abilities and subjective hearing aid satisfaction were evaluated.

Results All the open-set speech recognition performances of the TG were enhanced after the closed-set auditory training, while the performance of the NTG was not significantly changed. The auditory training had a positive impact on the TG individuals' subjective satisfaction of hearing aids. The improvement from training was maintained over one month after the completion of the auditory training.

Conclusion The closed-set auditory training protocol might lead to enhanced speech understanding as well as more satisfaction with hearing aids for adult hearing aid users. Korean J Otorhinolaryngol-Head Neck Surgg 2021;64(2):70-6

Key Words Auditory rehabilitation · Closed-set auditory training · Hearing aid user.

\begin{abstract}
서 론
청각손실은 65 세 이상 고령자의 만성질환 중 하나로 ${ }^{1)}$ 개인 의 일상생활에 부정적인 영향을 미칠 수 있다. 청각손실로 인

This is an Open Access article distributed under the terms of the Creative Commons Attribution Non-Commercial License (https://creativecommons.org/licenses/by-nc/4.0) which permits unrestricted non-commercial use, distribution, and reproduction in any medium, provided the original work is properly cited.
\end{abstract}

하여 소리의 근원을 비롯한 언어의 이해, 방향성 확인 등과 같은 어려움이 발생할 수 있으며, ${ }^{2)}$ 간접적으로는 사회적 고 립, ${ }^{3)}$ 우울, ${ }^{4)}$ 몸의 균형, ${ }^{5}$ 심혈관 질환, ${ }^{6)}$ 당뇨, 치매 ${ }^{8)}$ 등의 문제 와 연관될 수 있다. 청각손실이 있음에도 중재를 받지 않을 경우 본인은 물론 가족, 동료와의 관계에도 부정적인 영향을 미칠 수 있다. ${ }^{9)}$

보청기는 대표적인 청력 재활도구 중 하나로 난청인의 귀에 
장착하여 소리를 증폭하여 주는 기기이다. 최근 다양한 기술 발전으로 인하여 보청기 착용 후 조용한 상황에서의 가청도 (audibility)와 소리의 질은 향상되었지만 다양한 일상 소음하 어음인지능력은 사용자들이 만족할만큼 개선되지 않았다. 성 공적으로 언어를 처리하기 위해서는 말초청각신경이 아닌 중 추청각처리 및 인지 시스템에서 음향신호를 코딩하고 통합하여 처리해야 하는데, 보청기를 통한 소리 증폭이 난청과 노화로 인한 중추청각처리 능력 저하를 만족스럽게 보상하지 못하여 다양한 소음 환경에서 의사소통 하는데 한계가 발생한다.10)

보청기만으로 의사소통의 불편함을 해소하지 못한 보청기 사용자에게 청능훈련을 시행할 경우 의사소통 능력이 향상하 고 보청기에 대한 만족도가 증가할 수 있다. ${ }^{11,12)}$ 청능훈련은 청각자극에 반응하는 뇌 가소성(brain plasticity)을 기반으로 그 원리를 설명한다. 청각 자극을 집중적으로 제시하는 청능 훈련을 시행할 경우 지속적이고 반복적인 청각자극이 새로운 신경네트워크를 생성하고 뇌가 학습하게 되어 결과적으로 뇌 가소성을 꾀할 수 있다. ${ }^{13)}$ 인간 혹은 동물을 대상으로 집중적 인 듣기 훈련 후 한 행동청각반응 및 청성유발전위 반응을 측 정한 결과, 중추청각시스템에 뇌 가소성이 발생하였음을 밝 혔다. ${ }^{10,14,15)}$ 청능훈련의 긍정적인 효과와 더불어 청능훈련으 로 개선된 어음인지능력이 훈련 종료 약 2개월 후, ${ }^{16)}$ 4개월 후, ${ }^{17)} 6$ 개월 후 ${ }^{18}$ 까지도 유지되어 청능훈련의 효과가 장기적으 로 유지될 수 있음이 보고된 바 있다.

청능훈련의 효과를 밝힌 다양한 연구에서 훈련 자극음의 종류, 총 훈련 기간, 주당 훈련 횟수, 훈련 절차, 훈련 효과의 정량화 방법 등이 서로 달랐다. ${ }^{19)}$ 청능훈련 효과를 밝힌 대 부분의 연구에서 난청인을 대상으로 보기가 없는 조건에서 (open-set) 무의미음절 혹은 일이음절 단어 등을 듣고 반복 하여 따라말하는 훈련을 주로 시행하였다. ${ }^{19)}$ 이러한 연구 디 자인은 특정 자극음에 대한 훈련 효과를 밝히는데 유리한 장 점이 있으나 30 50분 가량 동일한 훈련을 반복하게 되어 지 루함, 스트레스 등을 유발할 수 있다. ${ }^{20)}$ 특히 어음인지도가 낮 은 대상자의 경우 보기가 없는 조건에서 음소를 변별하거나
소음하에서 어음을 인지하는 것이 좌절감을 일으킬 수 있다.

따라서 본 연구에서는 보청기 착용 성인을 대상으로 세 가 지 종류의 자극음(환경음, 단어, 문장)을 활용하여 보기가 있 는(closed-set) 청능훈련 프로토콜을 시행하였다. 훈련의 효 과를 정량화하기 위하여 보기없는 조건(open-set)에서 객관 적 어음인지도(조용한 상황속 단어인지도, 소음하 단어인지 도 및 문장인지도)를 측정하고 주관적 보청기 만족도의 변화 를 확인하였다. 청능훈련군과 비훈련군의 결과를 비교하는 것 외에 훈련군의 경우 훈련 종료 1 개월에도 재평가를 실시하여 훈련의 효과가 유지되는지 평가하였다.

\section{대상 및 방법}

\section{대 상}

최소 2개월 이상 양이에 보청기를 사용 중인 난청 성인 22명 (남: 6명, 여: 16명)이 연구 대상자로 참여하였다. 22명 중 12명 은 청능훈련군(training group, $\mathrm{TG}$ )으로 참여하였고, 나머지 10 명은 청능훈련을 받지 않는 비훈련군(non-training group, $\mathrm{NTG)}$ 으로 참여하였다. 모든 연구 대상자는 난청 외에 다른 이과적 병력이 없었으며, 전기음향학적 보정을 시행한 GSIPELLO(Grason-Stadler Inc., Eden Prairie, MN, USA)와 DD45(RadioEar Corporation, New Eagle, PA, USA) 헤드폰을 사용하여 방음실에서 순음청력검사를 실시하였다. Table 1은 $\mathrm{TG}, \mathrm{NTG}$ 대상자의 평균 나이, 보청기 착용 전후 500, 1000, $2000 \mathrm{~Hz}$ 주파수의 양이 평균순음역치(pure tone threshold average, PTA), 보청기 착용 후 일상대화음레벨[65 dB sound pressure level(SPL)]에서 음장 평가로 측정한 양이 단어인지 도(word recognition score, WRS), 평균 보청기 사용 시간을 보여준다. 독립표본 $\mathrm{t}$ 검정 분석 결과 $\mathrm{TG}$ 와 $\mathrm{NTG}$ 대상자 간 나이, 보청기 착용 전후 측정한 주파수별 청력과 PTA, 보청기 착용 후 측정한 단어인지도, 하루 보청기 착용 시간 모두 통 계적으로 유의하게 다르지 않았다 $(p>0.05)$.

훈련을 시작하기 전 보청기 성능분석 장비(Affinity 2.0,

Table 1. Demographic characteristics of TG and NTG

\begin{tabular}{|c|c|c|}
\hline & TG & NTG \\
\hline$\overline{\text { Age }}$ & 72.17 years of age (SD: 8.93$)$ & 73.30 years of age (SD: 9.15) \\
\hline \multirow[t]{2}{*}{ Unaided PTA } & Left ear: $57.22 \mathrm{~dB}$ HL (SD: 13.66) & Left ear: $53.50 \mathrm{~dB}$ HL (SD: 7.31) \\
\hline & Right ear: $53.61 \mathrm{~dB} \mathrm{HL}$ (SD: 11.89) & Right ear: $57.33 \mathrm{~dB} \mathrm{HL}$ (SD: 12.67) \\
\hline \multirow[t]{2}{*}{ Aided PTA } & Left ear: $35.67 \mathrm{~dB}$ HL (SD: 5.65) & Left ear: $32.82 \mathrm{~dB}$ HL (SD: 6.54) \\
\hline & Right ear: 35.68 dB HL (SD: 4.52) & Right ear: $34.80 \mathrm{~dB}$ HL (SD: 10.30) \\
\hline \multirow[t]{2}{*}{ Aided WRS at conversational speech level ( $65 \mathrm{~dB}$ SPL) } & Left ear: $60.83 \%$ (SD: 15.87) & Left ear: $60.80 \%$ (SD: 13.96) \\
\hline & Right ear: 56.75\% (SD: 14.91) & Right ear: 61.90\% (SD: 17.21) \\
\hline Daily use of hearing aids & 9.25 hours (SD: 2.56$)$ & 9.60 hours (SD: 2.37 ) \\
\hline
\end{tabular}

TG: training group, NTG: non-training group, PTA: pure tone threshold average, WRS: word recognition score 
Interacoustics, Middelfart, Denmark)를 이용하여 대상자의 보청기 적합 상태를 확인하였고 매번 훈련을 시작하기 전 보 청기의 이상 유무를 확인하였다. 연구에 참여하기 전 대상자 들에게 본 연구의 목적, 방법 및 진행 절차에 대한 설명을 제 공하였으며 참여자들의 동의 후에 연구를 진행하였다(IRB: HUGSAUD439175).

\section{청능훈련 도구 및 절차}

청능훈련은 주 1 회 8 주간(총 8 회) 실시하였으며, 각 회당 청 능훈련 40분, 상담 20분으로 구성하였다. 환경음, ${ }^{21)}$ 단어, ${ }^{22}$ 문 장 ${ }^{23)}$ 을 훈련 자극음으로 사용하였고 대상자는 들은 음원을 보기 안에서 고르는(closed-set) 청능훈련을 시행하였다. 본 연구에서 사용한 자극음 중 $\mathrm{Ahn}$ 과 $\mathrm{Lee}^{21}$ 의 환경음은 청능 훈련을 목적으로 개발 및 검증한 것으로 $80 \%$ 이상의 인지도 를 보이는 친숙한 환경음(교통수단, 신체, 동물, 악기에 관련 된 소리와 실내외 환경음 등) 총 44 개의 음원을 포함한다. 대 상자가 각 환경음 음원을 듣고 5 개의 보기 중 들은 소리에 해 당하는 그림을 고를 수 있도록 제작되어 있다. Ryu 등 ${ }^{22}$ 의 단 어는 초성 혹은 종성 자음이 서로 다른 일음절 단어 총 300 개를 포함하며, 4 개의 보기를 이용하여 특정 자음의 인지를 목표로 훈련을 기획하는 것이 가능하다. 마지막으로 Lee 등 ${ }^{23)}$ 의 문장은 청능훈련을 목적으로 개발한 것으로 50 개(주어 10 개, 형용사 10 개, 목적어 10 개, 수사 10 개, 동사 10 개)의 보기 단어 중 5 개의 병렬식 단어 조합으로 문장이 이루어진다. 모 든 문장의 길이가 같고 동일한 구조를 가지며, $10^{5}$ 개의 조합 이 가능하므로 반복된 훈련을 시행해도 문장 자체를 외워서 대답할 가능성이 적다는 장점이 있다.

매 훈련 회기마다 세 가지 자극음(환경음, 단어, 문장 자극 음)을 모두 사용하였고 세 가지 자극음의 제시 순서는 무작위 로 변경하였다. 청능훈련의 난이도가 너무 쉬울 경우 대상자 가 훈련을 지루해 할 수 있고 훈련의 난이도가 너무 어려운 경우 대상자가 좌절감과 스트레스를 느낄 수 있다. 따라서 훈 련 시 대상자가 50 80\%의 정반응을 보일 수 있는 난이도를 유지하고자 보기의 개수, 듣기 조건[조용한 상황 $\rightarrow 9 \rightarrow 6 \rightarrow 3$ $\rightarrow 0 \mathrm{~dB}$ 신호대잡음비(signal-to-noise ratio, SNR)] 등을 조 절하였다. 훈련 시 대상자가 정반응을 보이지 못한 경우 피드 백으로 최대 3회까지 자극음을 들려주었다.

모든 자극음과 어음스펙트럼잡음 ${ }^{23}$ 의 실효값(root mean square)이 일정하도록 조절 후(Adobe Audition CC 2015, Adobe System Inc, San Jose, CA, USA) 조용한 상황 및 0, 3, 6, $9 \mathrm{~dB} \mathrm{SNR}$ 에서 자극음을 제시할 수 있도록 음원을 제작하였다. 훈련용 자극음은 대상자로부터 1미터 떨어진 스 피커(PISnet SoundBox, SAMJI-IT, Seoul, Korea)와 컴퓨
터(I5 9400F, ASSACOM, Seoul, Korea)를 통해 약 $70 \mathrm{~dB}$ SPL에서 제시하였다. 청능훈련은 소음측정기(TES-1350A sound level meter, TES Electrical Electronic Corp, Taipei, Taiwan)를 사용하여 소음 레벨이 $40 \mathrm{dBA}$ 이하의 방에서 시 행하였다.

\section{청능훈련 효과 평가}

청능훈련의 효과를 평가하기 위해 TG, NTG 대상자 모두 보청기 착용 후 동일한 시기에 총 3 회의 평가를 시행하였다. 훈련에 참여했던 $\mathrm{TG}$ 대상자에게는 청능훈련 시작 전인 0 주 (pre-training), 훈련이 끝난 8주(post-training), 청능훈련이 끝난 한 달 후인 12주(1-month follow-up)에 재평가를 받았 다. 훈련을 종료한지 1개월 후 재평가(1-month follow-up)를 시행한 이유는 훈련 종료 1 개월 후에 훈련 후 개선된 인지도가 유의하게 감소하지 않고 유지되는지를(retention effect) 확인 하기 위함이었다. NTG는 훈련에 참여하지 않았던 대상자이 므로 동일한 평가시기 $(0,8,12$ 주)에 재평가만을 시행하였다.

훈련 후 보기없이 측정한(open-set) 어음인지도의 변화를 확인하기 위해 한국어음청각검사 ${ }^{24}$ 의 녹음된 어음을 이용하 여 조용한 상황에서의 단어인지도(WRS), 소음하 WRS, 소음 하 문장인지도(sentence recognition score, SRS)를 측정하였 다. 소음하 단어인지도 및 문장인지도 측정을 위해 목표 어음 과 다화자 배경소음 25$)$ 이 $6 \mathrm{~dB} \mathrm{SNR에서} \mathrm{제시될} \mathrm{수} \mathrm{있도록} \mathrm{제}$ 작하였다(Adobe Audition CC 2015, Adobe System Inc). 평 가용 음원은 청력검사기(GSI-PELLO, Grason-Stadler Inc., Eden Prairie, MI, USA), 컴퓨터(I5 9400F, ASSACOM), 음 장검사용 스피커(JBL Control 1 Pro, JBL professional, Los Angels, CA, USA)를 통해 $65 \mathrm{~dB}$ SPL에서 제시하였다.

위의 객관적 평가 외에 청능훈련 전후 보청기 만족도의 변 화를 확인하기 위해 Korean version of International Outcome Inventory for Hearing Aids(K-IOI-HA ${ }^{26)}$ 설문을 시 행하였다. K-IOI-HA는 자가 보고형 보청기 사용자의 주관적 만족도 설문 도구이며, 총 7개의 문항(하루 평균 사용시간, 도 움의 정도, 사용 후 개선 정도, 보청기 사용의 가치, 보청기 사 용 후 불편 정도, 타인에게 미치는 부정적 상황, 삶의 질 개선 정도)으로 이루어져 있으며 구성개념 타당도를 만족한다. 7 개 문항당 최소 1점에서 최대 5점의 대답이 가능하여 최대 35점 의 점수가 가능하다.

\section{데이터 분석}

수집된 결과는 Statistical Product and Service Solution 25.0 (SPSS 25.0 version; IBM Corp., Armonk, NY, USA)을 이용 하여 분석하였다. 반복측정된 이원분산분석(two-way ANO- 
VA with repeated measures)을 시행하여, 그룹간 변수(TG vs. $\mathrm{NTG})$, 그룹 내 변수인 평가시기( $0,8,12$ 주)에 따라 조용한 상 황에서의 WRS, 소음하 WRS, 소음하 SRS가 유의하게 달랐 는지, 두 변수 간 상호작용(interaction)이 있는지 확인하였다. Mauchly의 구형성 가정이 위배된 경우 Greenhouse-geisser 수정된 F값과 자유도를 보고하였다. Wilcoxon 부호순위 비 모수 검정을 통해 두 그룹(TG, NTG) 간 K-IOI-HA 보청기 만 족도 설문 결과를 비교하였다. Pearson 상관분석 혹은 Spearman 비모수 상관분석을 통하여 객관적 어음인지도 향상 간 상관성, 객관적 결과와 주관적 설문 결과간 상관성 등을 확인 하였다. 모든 분석은 $p<0.05$ 를 기준으로 유의성을 확인하였 고, 유의한 주효과로 다중비교가 필요한 경우 1 종 오류의 증 가를 조정하기 위해서 Bonferroni correction을 적용하였다.

\section{결 과}

\section{평가시기에 따른 평균 어음인지도}

보기가 있는 청능훈련 프로토콜의 효과를 평가하기 위해 대상자 모두 동일한 평가시기 $(0,8,12$ 주)에 보기를 제시하지 않고(open-set) 조용한 상황 속 WRS, 소음하 WRS, 소음하 $\mathrm{SRS}$ 를 측정하였다. 평가시기에 따른 두 그룹의 평균 어음인 지도는 Fig. 1에 나타내었다. 먼저 TG 대상자의 인지도를 살 펴보면(Fig. 1A), 훈련 전(0주), 훈련 후(8주), 훈련 종료 1개월 후(12주)의 평가시기 순서대로 조용한 상황 속 WRS는 평균 58.79\%(표준편차: 13.77), 72.33\%(표준편차: 12.67), 72.71\% (표준편차: 13.15)이었고, 소음하 평균 WRS는 위의 평가시기 순서대로 52.75\%(표준편차: 17.85), 68.79\%(표준편차: 20.07), 70.42\%(표준편차: 18.87), 마지막으로 소음하 평균 SRS는 위 의 평가시기 순서대로 $65.75 \%$ (표준편차: 24.08), $77.58 \%$ (표준
편차: 26.37), 78.71\%(표준편차: 26.91)이었다. NTG 대상자의 인지도를 살펴보면(Fig. 1B), 0, 8, 12주의 순서대로 조용한 상 황에서의 WRS는 평균 $61.35 \%$ (표준편차: 13.08), 63.95\%(표 준편차: 13.03), 65.25\%(표준편차: 12.50)이었고, 평균 소음하 WRS는 55.10\%(표준편차: 16.69), 59.80\%(표준편차: 15.55), 60.15\%(표준편차: 15.30), 평균 소음하 SRS는 $68.60 \%$ (표준편 차: 14.79), 71.45.\%(표준편차: 15.70), 71.65\%(표준편차: 15.96) 이었다.

평가시기 $(0,8,12$ 주)와 그룹(TG, NTG)에 따른 주효과, 평 가시기와 그룹 간 이원상호작용을 확인하기 위해 반복측정된 이원분산분석을 시행하였다. 먼저 평가시기에 따른 주효과는 모든 결과에서 유의하였다[조용한 상황 WRS: F(1.15, 22.99) =59.32; 소음하 WRS: F(1.33, 26.61)=53.78, 소음하 SRS: F $(1.25,25.00)=23.02]$. 그룹에 따른 주효과는 모든 결과에서 유 의미하지 않았다[조용한 상황 WRS: $\mathrm{F}(1,20)=0.65$; 소음하 WRS: $\mathrm{F}(1,20)=0.58$; 소음하 SRS: $\mathrm{F}(1,20)=0.14]$. 평가시기 와 그룹 간 이원상호작용은 모든 평가결과에서 유의하였다[조 용한 상황 WRS: $F(1.15,22.99)=22.56$; 소음하 WRS: $F(1.33$, 26.61)=16.38; 소음하 SRS: $\mathrm{F}(1.25,25.00)=8.73]$. 즉 평가시기 에 따른 인지도 변화 패턴이 두 그룹간 달랐음을 의미한다.

이원상호작용이 유의하였으므로 $\mathrm{TG}$ 와 NTG 대상군 각각 의 결과에서 평가시기에 따른 주효과와 Bonferroni 수정된 다중비교 결과를 확인하였다. TG 대상자의 경우 청능훈련 전 (0주) 보다 청능훈련 후(8주) 모든 인지도가 유의하게 향상하 였고, 청능훈련 후(8주) 보다 훈련 종료 1개월 후(12주) 인지도 에 유의한 변화가 없었다[조용한 상황 WRS: F(1.07, 11.73) $=53.41$; 소음하 WRS: $F(1.19,13.14)=20.28$; 소음하 SRS: $F$ $(1.19,13.14)=20.28] . \mathrm{NTG}$ 의 경우 모든 결과에서 평가시기에 따른 유의한 변화가 없었다.

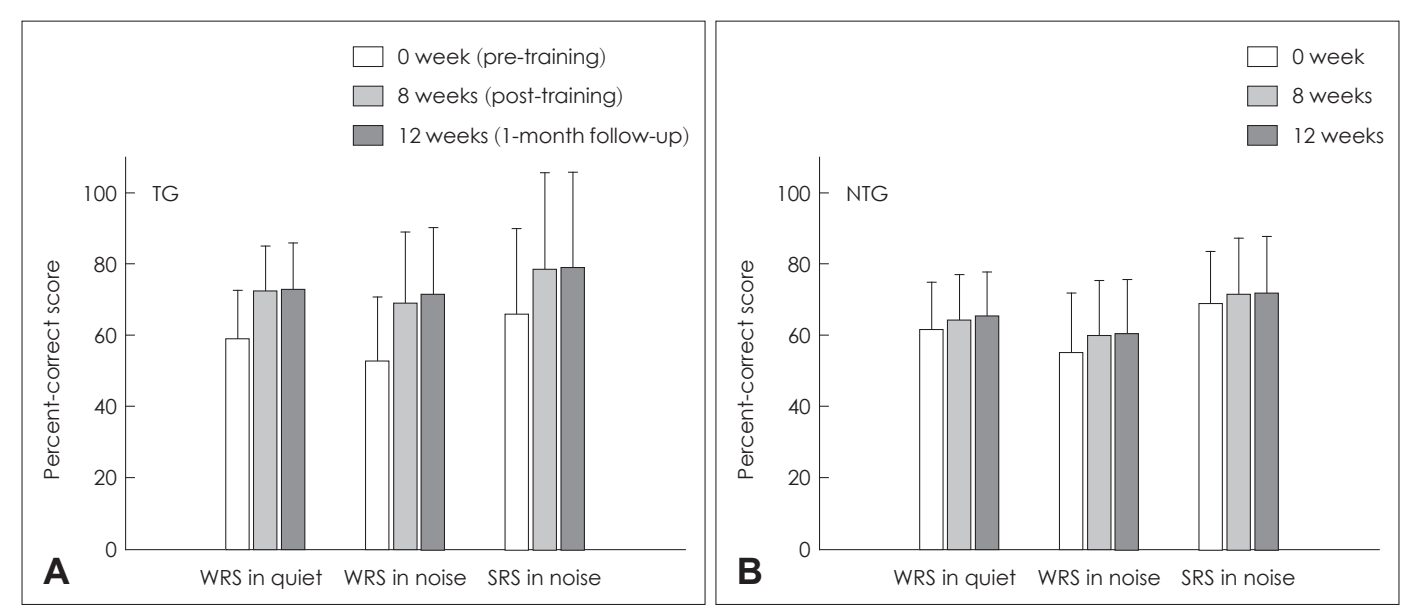

Fig. 1. Mean aided speech recognition scores obtained from three test periods $(0,8,12$ weeks) in TG (A) and NTG (B) (error bar: standard deviations). TG: training group, NTG: non-training group, WRS: word recognition score, SRS: sentence recognition score. 
평가시기에 따른 개인별 어음인지도

청능훈련 효과를 확인할 때는 훈련 후 평균 인지도가 증가 하였는지를 보는 것 외에 훈련에 참여한 대상자 개개인의 인 지도가 모두 향상하였는지를 확인하는 것이 중요하다. 따라서 훈련에 참여한 TG 대상자 12 명의 인지도 향상 정도를 Fig. 2 에 제시하였다. 인지도 향상 정도는 훈련 후(8주) 측정한 인지 도에서 훈련 전(0주) 측정한 인지도를 빼 계산하였다.

먼저 조용한 상황에서 측정한 WRS는 평균 $13.54 \%$ 향상하 였고(Fig. 2A), 소음하 WRS는 $16.04 \%$ (Fig. 2B), 소음하 SRS 는 $12.7 \%$ 증가하였다. 여기서 주목할 점은 12 명 대상자 모두 훈련 전보다 훈련 후 조용한 상황의 WRS와 소음하 WRS가 향상하였고, S11을 제외한 11명 대상자 모두 훈련 후 소음하 $\mathrm{SRS}$ 가 증가하였다. 이 중 S7 대상자의 경우 조용한 상황의 $\mathrm{WRS}$ 가 $27 \%$, 소음하 WRS가 $31.5 \%$, 소음하 SRS가 $22.5 \%$ 향상하여 모든 조건에서 인지도 향상 정도가 비교적 컸던 대
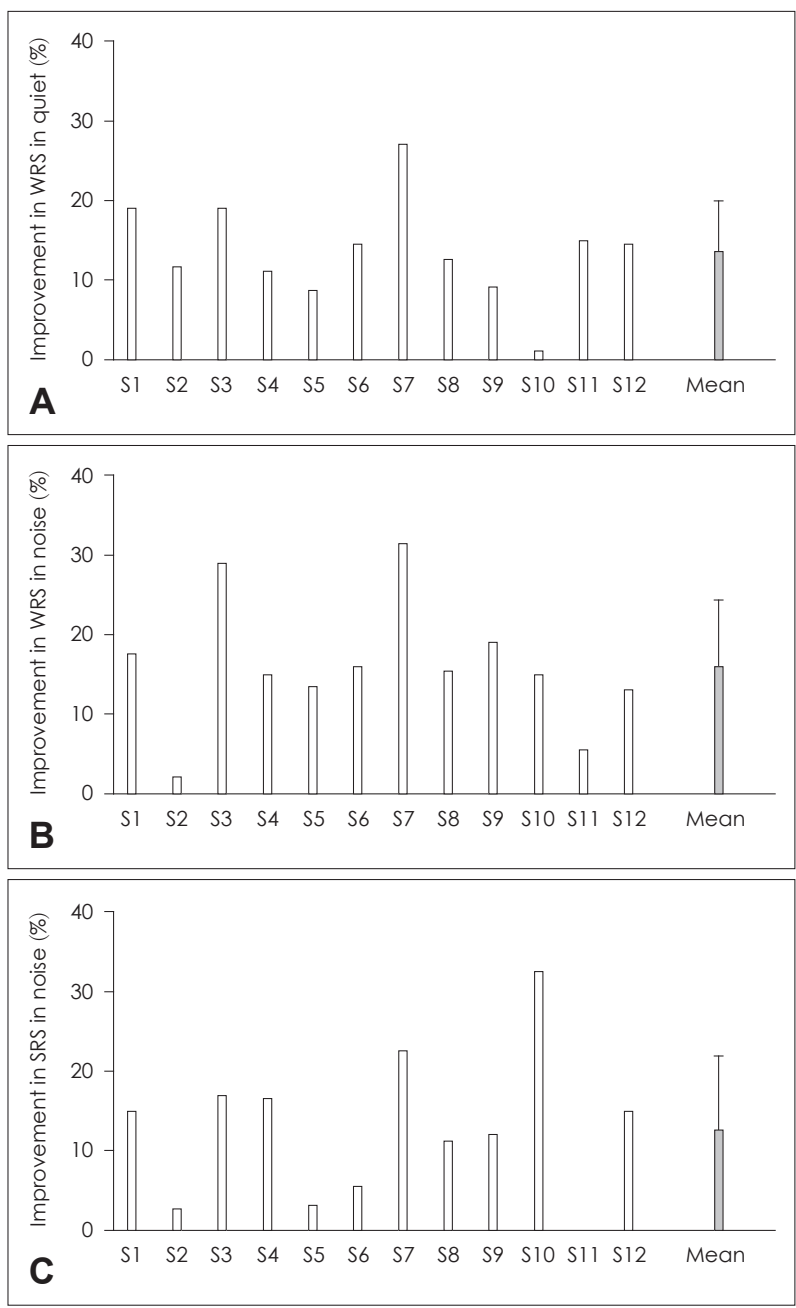

Fig. 2. Individual improvements of training group in speech recognition scores (error bar: standard deviations). S: subject, WRS: word recognition score, SRS: sentence recognition score.
상자 중 하나였다. 각 조건에서 측정한 개인별 인지도 향상 정 도 간 상관성이 있는지 Pearson 상관분석을 시행한 결과 유 의한 상관성이 관찰되지 않았다 $(p>0.05)$. 즉, 조용한 상황에 서 인지도가 많이 향상하였다고 소음상황에서의 인지도가 많이 증가한 것은 아니었다.

\section{평가시기에 따른 주관적 보청기 만족도}

본 연구에서는 0 주와 8주에 K-IOI-HA ${ }^{26)}$ 설문을 실시하여 훈련 전후 주관적 보청기 만족도의 변화를 확인하였다. $\mathrm{TG}$ 대상자의 경우, 훈련 전(0주)에 측정한 평균 $\mathrm{K}-\mathrm{IOI}-\mathrm{HA}$ 점수 는 26.4점(표준편차: 1.7), 훈련 후(8주)에 측정한 평균 $\mathrm{K}-\mathrm{IOI}-$ $\mathrm{HA}$ 점수는 29.5점(표준편차: 1.9)으로 3.1점 가량 증가하였다. $\mathrm{NTG}$ 대상자의 경우 0주와 8주에 측정한 점수가 각각 27.4점 (표준편차: 1.9), 27.7점(표준편차: 2.3)이었다. Wilcoxon 부호 순위 비모수 검정 결과 $\mathrm{TG}$ 대상자는 훈련 전(0주)에 비해 훈 련 후(8주) $\mathrm{K}-\mathrm{IOI}-\mathrm{HA}$ 점수가 유의하게 증가였으나(Z=-3.1), NTG 대상자의 0 주와 8주 K-IOI-HA 점수는 유의하게 다르 지 않았다 $(\mathrm{Z}=-1.3)$.

청능훈련 후 TG 대상자 개개인의 K-IOI-HA 변화를 확인 하여 Fig. 3에 나타내었다. 그림을 통해 알 수 있듯이 TG 대상 자 12명 모두 K-IOI-HA 점수가 최소 2점부터(S2, S5, S11) 최 대 5점(S8) 증가하였다. 주관적 보청기 만족도 변화 정도와 객 관적 인지도 변화 정도 간 상관성이 있는지 spearman 상관분 석을 시행한 결과 TG 대상자의 $\mathrm{K}-\mathrm{IOI}-\mathrm{HA}$ 변화와 WRS, SRS 인지도 향상 정도 간 유의한 상관성이 없음을 확인하였다 $(p>0.05)$. 이는 훈련 후 객관적 어음인지도 결과가 향상하였 을지라도 실제로 대상자가 주관적으로 느끼는 보청기 만족도 는 증가하지 않을 수 있음을 의미한다.

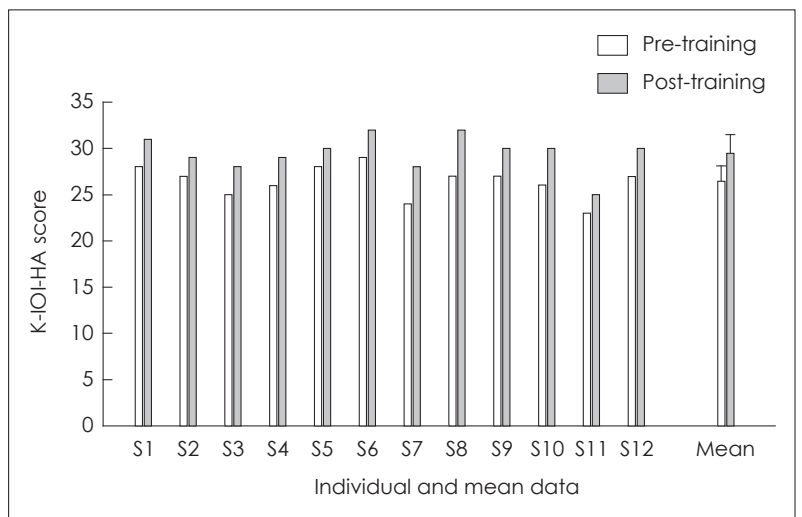

Fig. 3. Individual and mean K-IOI-HA scores of training group obtained from pre-training and post-training tests (error bar: standard deviations). S: subject, K-IOI-HA: Korean version of International outcome Inventory for Hearing Aids. 


\section{고 찰}

보기 없이(open-set) 어음인지평가가 불가능한 경우 보기 가 있는(closed-set) 어음인지능력의 평가가 필요하듯이, ${ }^{27)}$ 보 기가 없는 청능훈련(open-set auditory training)이 어려운 경 우 보기가 있는 청능훈련(closed-set auditory training)이 효 과적일 수 있다. 다양한 연구자들이 청능훈련의 긍정적인 효 과를 밝혔으며, 각 연구마다 훈련에 참여한 대상군, 훈련 자극 음 종류, 훈련 빈도, 회차별 훈련 시간 및 기간, 훈련 절차 및 훈련의 평가 방법 등에는 차이가 있었으나 공통적으로 청능 훈련 후 어음인지도가 향상하였다. ${ }^{11,12,16-20,28-30)}$ 본 연구에서는 양이 보청기 착용 성인을 대상으로 보기가 있는 청능훈련 프 로토콜을 이용하여 8주간 훈련을 시행하였다. 훈련의 효과를 정량화하기 위해 훈련군과 비훈련군을 대상으로 보기를 제시 하지 않고(open-set) 단어인지도와 문장인지도를 측정하였고 더불어 주관적 보청기 만족도를 평가하였다.

분석 결과 어음의 종류나 듣기 조건에 상관없이 청능훈련 에 참여한 TG군만 인지도가 향상하여(약 13 16\%) 보기가 있 는 훈련 프로토콜만을 사용하였음에도 불구하고 보기 없이 측정한 객관적 어음인지도가 긍정적으로 변화하였음을 알 수 있었다. 평균적으로 인지도가 향상한 것뿐 아니라 TG 대상자 대부분이 훈련으로 객관적 어음인지도와 보청기 만족도가 증 가하였다. 본 연구와 유사하게 Lee 등기는 보청기 착용 아동 에게 문장을 제시하고 문장 내 단어를 그림 보기를 통해 맞 추는 청능훈련을 시행하였다. 분석 결과 그림 보기를 이용한 청능훈련이 유의하게 어음인지도를 향상시킬 뿐 아니라 훈련 종료 4개월 후까지 훈련으로 인해 개선된 인지도가 유의하게 변화하지 않았다고 밝혔다.

본 연구에서도 훈련 후 향상된 인지도가 훈련이 종료된 1개 월 후에도 유의하게 저하되지 않고 유지됨(retention)을 확인 하였다. 이러한 훈련효과의 유지는 다양한 선행연구에서도 확인된 바 있다. 인공와우 착용 성인에게 보기가 있는 조건에 서 숫자를 이용하여 훈련을 시행한 결과 훈련 후 소음하 어음 인지가 증가하였고 훈련 종료 1개월후까지 훈련의 효과는 유 지되었다. ${ }^{29)} 43$ 명의 보청기 착용 성인을 대상으로 재택 청능훈 련(at-home auditory training)을 시행한 결과 훈련 종료 후 8 개월까지 훈련 효과가 유지되었음을 밝혔다. ${ }^{30)}$ 이와 같이 훈 련 종료 후 훈련 효과가 유지되었던 것은 청능훈련으로 인하 여 습득한 새로운 기술을 장기기억으로 효과적으로 잘 저장 되었다고 볼 수 있다. 학습으로 인한 기억은 뉴런의 시냅스 가소성과 관련이 있으며 뇌 이미지 연구와 전기생리 연구에 서 청능훈련으로 인해 중추청각시스템의 가소성이 발생할 수 있음을 증명하였다. ${ }^{14}$
본 연구에 참여했던 $\mathrm{TG}$ 훈련 대상자 12 명 중 $\mathrm{S} 4, \mathrm{~S} 5, \mathrm{~S} 7$, S12는 80대 보청기 착용 노인이었다. Fig. 2에 제시한 개개인 별 인지도 향상 정도를 살펴보면 80대 보청기 사용자였던 S4, $\mathrm{S} 5, \mathrm{~S} 7, \mathrm{~S} 12$ 모두 소음하 WRS가 $13 \%$ 이상 증가하였다. 특히 85세 대상자였던 S7은 훈련 전보다 훈련 후 조용한 상황속 $\mathrm{WRS}$ 는 $27 \%$, 소음하 WRS와 SRS가 $32 \%, 23 \%$ 가량 증가하 여 가장 많은 향상을 보인 대상자이었다. 본 연구 결과를 통 해 청능훈련을 통해서 보청기 착용 노인의 소음하 어음인지 능력도 향상될 수 있다는 것을 확인하였다. 후속 연구에서는 청능훈련을 통한 어음인지능력의 향상 뿐 아니라 노인의 삶의 질, 우을 정도의 변화에 대한 평가가 함께 이루어지면 좋을 것 이며, 훈련을 위해 기관을 방문하는 것이 어려운 대상자를 고 려하여 재택 청능훈련의 효과를 확인하는 것이 필요하겠다.

\section{Acknowledgments}

This work was supported by the Ministry of Education of the Republic of Korea and the National Research Foundation of Korea (NRF-2019S1A5A2A01039904).

\section{Author Contribution}

Conceptualization: Jae Hee Lee, Junghwa Bahng. Data curation: Ji Young Jung. Formal analysis: Jae Hee Lee, Ji Young Jung. Funding acquisition: Junghwa Bahng. Investigation: Ji Young Jung. Methodology: Ji Young Jung. Project administration: Jae Hee Lee. Resources: Junghwa Bahng. Supervision: Jae Hee Lee. Validation: Jae Hee Lee. Visualization: Ji Young Jung. Writing — original draft: Ji Young Jung, Jae Hee Lee. Writing — review \& editing: Jae Hee Lee, Junghwa Bahng.

\section{ORCIDs}

Jae Hee Lee

https://orcid.org/0000-0002-4152-6434

Junghwa Bahng

\section{REFERENCES}

1) Jung YH, Ko SJ, Kim EJ. Research Report 2013-31-19: A study on the effective chronic disease management. Seoul: Korea Institute for Health and Social Affairs;2013.

2) Souza P, Hoover E, Blackburn M, Gallun F. The characteristics of adults with severe hearing loss. J Am Acad Audiol 2018;29(8):76479.

3) Sung YK, Li L, Blake C, Betz J, Lin FR. Association of hearing loss and loneliness in older adults. J Aging Health 2016;28(6):979-94.

4) Mener DJ, Betz J, Genther DJ, Chen D, Lin FR. Hearing loss and depression in older adults. J Am Geriatr Soc 2013;61(9):1627-9.

5) Lin FR, Ferrucci L. Hearing loss and falls among older adults in the United States. Arch Intern Med 2012;172(4):369-71.

6) Friedland DR, Cederberg C, Tarima S. Audiometric pattern as a predictor of cardiovascular status: Development of a model for assessment of risk. Laryngoscope 2009;119(3):473-86.

7) Bainbridge KE, Hoffman HJ, Cowie CC. Diabetes and hearing impairment in the United States: Audiometric evidence from the National Health and Nutrition Examination Survey, 1999 to 2004. Ann Intern Med 2008;149(1):1-10.

8) Osler M, Christensen GT, Mortensen EL, Christensen K, Garde E, Rozing MP. Hearing loss, cognitive ability, and dementia in men age 19-78 years. Eur J Epidemiol 2019;34(2):125-30. 
9) Vas V, Akeroyd MA, Hall DA. A data-driven synthesis of research evidence for domains of hearing loss, as reported by adults with hearing loss and their communication partners. Trends Hear 2017;21:2331216517734088.

10) Moossavi A, Aghazadeh J. Efficacy of auditory training in older adults by electrophysiological tests. Aud Vestib Res 2019;28(3):14657.

11) Kim J, Lee K. Effects on word and sentence recognition by auditory training using environmental sound for elderly hearing impaired. Audiol Speech Res 2017;13(2):115-22.

12) Jo YY, Bahng J, Lee JH. Case study of auditory training for an elderly hearing aid users. Audiol 2013;9(2):190-4.

13) Näätänen R, Schröger E, Karakas S, Tervaniemi M, Paavilainen P. Development of a memory trace for a complex sound in the human brain. Neuroreport 1993;4(5):503-6.

14) Anderson S, Kraus N. Auditory Training: Evidence for Neural Plasticity in Older Adults. Perspect Hear Hear Disord Res Res Diagn 2013;17:37-57.

15) Song JH, Skoe E, Banai K, Kraus N. Training to improve hearing speech in noise: Biological mechanism. Cereb Cortex 2012;22(5): 1180-90.

16) Burk MH, Humes LE. Effects of long-term training on aided speechrecognition performance in noise in older adults. J Speech Lang Hear Res 2008;51(3):759-71.

17) Lee Y, Hwang H, Lee JH. Efficacy of auditory training on speech recognition in children wearing hearing aids. Audiol Speech Res 2019;15(4):249-57.

18) Burk MH, Humes LE, Amos NE, Strauser LE. Effect of training on word-recognition performance in noise for young normal-hearing and older hearing-impaired listeners. Ear Hear 2006;27:263-78.

19) Henshaw H, Ferguson MA. Efficacy of individual computer-based auditory training for people with hearing loss: A systematic review of the evidence. PLoS One 2013;8(5):e62836.
20) Lee JH, Lee SG, Bahng J. Case study of auditory training for longterm users of hearing aids with poor word recognition. Audiol Speech Res 2016;12(3):190-4.

21) Ahn P, Lee K. Development of environmental sounds for auditory training. Audiol Speech Res 2016;12(2);82-8.

22) Ryu HD, Shim HY, Kim JS. A study on the relation between Korean consonant perception test (KCPT) and hearing thresholds as a function of frequencies. Audiol 2011;7(2):153-63.

23) Lee JW, Yi DW, Lee J, Lee JH. A preliminary evaluation of multiplechoice sentences developed for auditory training. Audiol Speech Res 2016;12(2):97-102.

24) Lee JH, Cho SJ, Kim JS, Jang HS, Lim DH, Lee KW, et al. Korean speech audiometry (KSA). Seoul: Hakjisa;2010.

25) Shin JB, Lee JH. Effects of the target talker gender and the number of competing talkers on Acceptable Noise Level (ANL) of Korean normal-hearing adults. Audiol 2010;6(2):146-52.

26) Chu H, Cho YS, Park SN, Byun JY, Shin JE, Han GC, et al. Standardization for a Korean Adaptation of the International Outcome Inventory for Hearing Aids: Study of validity and reliability. Korean J Otorhinolaryngol-Head Neck Surg 2012;55(1):20-5.

27) Clopper CG, Pisoni DB, Tierney AT. Effects of open-set and closedset task demands on spoken word recognition. J Am Acad Audiol 2006;17(5):331-49.

28) Yeo SH, Bahng JH, Lee JH. Efficacy of auditory training using sentences in noise for hearing aid users. Audiol 2014;10(1):65-75.

29) Oba SI, Fu QJ, Galvin JJ 3rd. Digit training in noise can improve cochlear implant users' speech understanding in noise. Ear Hear 2011;32(5):573-81.

30) Humes LE, Skinner KG, Kinney DL, Rogers SE, Main AK, Quigley TM. Clinical effectiveness of an at-home auditory training program: A randomized controlled trial. Ear Hear 2019;40(5):1043-60. 